\title{
ВЫЗОВЫ И УГРОЗЫ СОВРЕМЕННОГО МИРА НА ПРИМЕРЕ МИГРАЦИОННОГО КРИЗИСА США
}

\author{
И. С. Улыбин \\ Московский гуманитарный университет
}

\begin{abstract}
Аннотация: В статье рассматриваются проблемы легальной и нелегальной иммиграции в США: причины и последствия нелегальной миграции, вызовы и угрозы, создаваемые нелегальными иммигрантами, государственная политика в период пребывания у власти Д. Трампа. Проводится сравнительный анализ деятельности президентов США с 1986 г. по настоящее время.

Текст доклада автора на Общероссийской (национальной) научной конференции «Моисеевские чтения. Культура и гуманитарные проблемы современной цивилизации», которая состоялась 4-5 марта 2020 г. в Московском гуманитарном университете.
\end{abstract}

Ключевые слова: США; миграционная политика; легальная миграция; нелегальная миграция; стена Трампа; депортация; права человека

\section{CHALLENGES AND THREATS OF THE CONTEMPORARY WORLD UNDER MIGRATION CRISIS IN THE USA}

\author{
I. S. Ulybin
}

Moscow University for the Humanities

\begin{abstract}
The article deals with the issues of legal and illegal migration to the USA. Covered are the reasons and consequences of illegal migration to the USA, the challenges and threats posed by illegal immigrants, the state policy in this sphere during the presidency of Donald Trump. A comparative analysis of US presidents' actions since 1986 to nowadays is conducted.

The text of the author's speech at the All-Russian (National) Scientific Conference "Moiseev's Readings. The Culture and Humanitarian Issues of Modern Civilisation", which was held at Moscow University for the Humanities on 4-5 March, 2020.
\end{abstract}

Keywords: USA; migration policy; legal migration; illegal migration; Trump wall; deportation; human rights

Сегодня проблема нелегальной иммиграции является достаточно серьезной угрозой для мира - начиная от проблемы беженцев из ближневосточных стран в государства ЕС и заканчивая проблемой нелегальной миграции из Южной Америки в США. В данной статье я хотел бы рассмотреть этот вопрос на примере миграции в Соединенные Штаты Америки.

Стабильное состояние экономики США, а также высокий уровень жизни в стране привлекают большое количество мигрантов, в том числе нелегальных. Это вызывает опасения граждан, рабочие места которых могут занимать иммигранты.

Администрация Дональда Трампа также считает, что мигранты забирают большую часть льгот, положенных гражданам США от государства. Сам Трамп построил предвыборную компанию на лозунге «Америка для американцев» и всячески выступал за снижение количества легальных иммигрантов (уменьшение количества рабочих виз, прошений о политическом убежище, отмена лотереи Гринкард), также он очень резко был настроен на закрытие программы DACA ${ }^{1}$, которую

${ }^{1}$ Deferred Action for Childhood Arrivals - программа, которая включает в себя отсроченные действия депортации для детей мигрантов, прибывших в возрасте до 16 лет включительно. 
создал Барак Обама для детей нелегальных мигрантов прибывших в США в возрасте до 16 лет. По мнению Трампа, данная программа является антиконституционной и должна быть прекращена, но суды США не смогли принять единогласное решение (4 против 4), что пока оставило данную программу в рабочем состоянии.

Сегодня США сталкивается с рядом серьёзных проблем в сфере миграции, включая массовый наплыв незаконных иммигрантов через протяжённую и плохо охраняемую границус Мексикой — страной со значительно более низким, чем в США, уровнем жизни. В свою очередь, иммиграционный поток ведёт к росту социальной напряжённости и рассматривается многими в качестве угрозы, как безопасности страны, так и культурной идентичности американского населения. В связи с этим весьма интересно рассмотреть, как реагирует американское государство и общество на вызовы иммиграции.

План строительства стены на юго-западной границе США и Мексики, что было одной из основных частей предвыборной программы Трампа, заключался в постройке стены вдоль границы за счет Мексики. Мексика отказалась платить за столь дорогую конструкцию, объяснив это тем, что данная проблема больше волнует США, чем Мексику и у страны сейчас нет такой финансовой возможности. Это привело к некоторому ухудшению отношений между двумя государствами. Позже, Дональд Трамп сообщил, что США начнут строительство стены за свой счет, а Мексика в дальнейшем поможет в оплате строительства, но, чтобы начать его раньше, данную стену придется создавать за счет Соединенных Штатов. Из-за этого с 22 декабря 2018 г. в США произошло явление «шатдаун» ${ }^{1}$ - частичная остановка работы федерального правительства. Причиной закрытия госучреждений стал несогласованный бюджет из-за разногласий между Конгрессом и Белым домом. Трамп высказал намерения наложить вето на любой законопроект о расходах, который бы не включал 5 млрд \$ в финансирование строительства стены ${ }^{2} .4$ января 2019 г. Трамп выступил с заявлением, что бывшие президенты США в частных беседах с ним сказали, что они должны были построить данную пограничную стену, но на сегодняшний день все бывшие президенты США отрицают данную информацию. Трамп также заявил, что 90\% наркотических веществ, продаваемых в Америке, попадают в страну через южную границу ${ }^{3}$ По мнению президента, также стоить сократить количество людей, въезжающих для рассмотрения запроса на политическое убежище, так как по законам США, для того, чтобы человек имел возможность подать данное прошение, он должен находится на территории

\footnotetext{
${ }^{1}$ Приостановка работы правительства США (англ. government shutdown) — временная ситуация в США, возникающая, когда конгрессу не удаётся согласовать финансирование деятельности государственных органов. На время приостановления некритичные органы закрываются, а сотни тысяч их работников отправляются в неоплачиваемый отпуск. Обычно приостановление не относится к важнейшим организациям и ведомствам, жизненно важным для обеспечения безопасности государства, таким как армия. Однако из-за того, что расходы бюджета устанавливаются решением Конгресса, возможна остановка финансирования и работы любой государственной организации.

${ }^{2}$ Ferris S. and Caygle H, Politico, "Dems brace for pre-Christmas deadline crash" [Электронный ресурс] URL: https://www.politico.com/news/2019/12/06/house-democrats-legislative-deadlines-077181 (дата обращения: 22.02.2020).

${ }^{3}$ Kelly M., Washington Post, "Most imported heroin comes through legal points of entry" [Электронный pecypc] URL: https://www.washingtonpost.com/politics/2019/live-updates/trump-white-house/live-factchecking-and-analysis-of-president-trumps-immigration-speech/most-imported-heroin-comes-through-legalpoints-of-entry/?arc404=true (дата обращения: 24.02.2020)
} 
Соединенных Штатов. В данный момент количество одобренных разрешений на въезд, связанных с этим вопросом, составляет около 20\%. Также Дональд Трамп принял решение о кадровой помощи патрулям DHS ${ }^{1}$. Армия США будет патрулировать границу вместе с таможенными органами. В случае необходимости военным разрешено применять оружие и стрелять на поражение.

Как мигранты могут представлять опасность для США и Мексики? И какова та опасность, которая грозит самим мигрантам, пока они находятся в приграничных территориях Америки?

К 2007 г. численность населения США уже превысила 300 млн человек. Такой рост стал возможен как благодаря относительно высоким темпам естественного прироста, так и вследствие широкомасштабной иммиграции. Соединённые Штаты остаются единственной высокоразвитой страной мира, в которой население продолжает расти достаточно высокими темпами. Как ожидается, к 2050 г. оно достигнет 438 млн человек. Ежегодно население США растает приблизительно на 2 млн человек за счет естественного прироста и на 1 млн - вследствие легальной иммиграции ${ }^{2}$. Ещё около 800 тыс. чел. пересекают границу нелегально. Если бы иммиграции не было, население США все равно росло бы - и сейчас, и в обозримом будущем, но темпы роста были бы совсем иными.

За 2001-2005 годы почти две трети легальных иммигрантов прибыли по линии воссоединения семей, $17 \%$ получили визы в связи с трудоустройством в США, а 11\% прибыли в качестве беженцев.

Особое внимание сегодня уделяется тем аспектам иммиграции, которые связаны с возможностями проникновения в странутеррористов ичленов организованных преступных групп и контролем международных финансовых потоков, в том числе и нелегальным переводам мигрантов через границу. В настоящее время в качестве первоочередной угрозы, связанной с иммиграцией, рассматриваются именно те её аспекты, что связаны с терроризмом и угрозой безопасности страны. Соответственно, правоохранительная ориентация в работе иммиграционной службы усилилась, что нашло отражение и в структурных реформах последних лет.

В начале 2004 г. Президент Джордж Буш выступил с новой законодательной инициативой, направленной на частичное решение проблемы нелегальной иммиграции. Два момента заслуживают в этой связи особого упоминания. Во-первых, Буш планировал выдвинуть её ещё в самом начале своего президентства, но был вынужден отсрочить своё начинание в связи с терактами в сентябре 2001 г. и последовавшим за ними ужесточением иммиграционного контроля, а также общим ухудшением отношений с Мексикой, отказавшейся поддержать американские действия в Ираке. Во-вторых, интересен тот факт, что Буш, опирающийся, как и Рейган в 1986 г., на поддержку консервативных политических слоев, выступил с довольно либеральной иммиграционной платформой, пойдя против значительной части Республиканской партии.

\footnotetext{
${ }^{1}$ Министерство внутренней безопасности США, также Министерство национальной безопасности (МНБ) США (англ. Department of Homeland Security, DHS) - один из исполнительных департаментов правительства США.

2 Десятилетний прирост населения США примерно соответствует его величине в Калифорнии, крупнейшем американском штате. При этом ожидается, что в период 2005-2050 гг. 82\% прироста населения обеспечат иммигранты или их потомки в первом поколении (U.S. Population Projections: 20052050. Pew Hispanic Center.)
} 
Новая страница в иммиграционном вопросе открылась летом 2007 г., когда Палата представителей начала рассматривать законодательную инициативу, которая была значительно либеральнее, чем та, которая обсуждалась в 2006 г. Президент поставил на карту свою репутацию, лично приехав в Конгресс, чтобы поддержать законопроект, что случается крайне редко. Тем не менее, и эта компромиссная инициатива была провалена, во многом из-за политической слабости Буша, и трудно было рассчитывать на принятие радикальных мер в этой сфере до прихода более либеральной администрации Барака Обамы в Белый дом 20 января 2009 г.

Также важно оценить и экономические потери США, связанные с миграцией. Оценки экономических последствий иммиграции достаточно противоречивы. Степень вовлеченности иммигрантов в экономически активную деятельность на 7\% пунктов выше, чем у местного населения: 57\% по сравнению с 50\%. Объём ВВП, производимого иммигрантами, оценивается в 1,43-1,62 трлн. \$, что приблизительно равно ВВП Калифорнии. На иммигрантов приходится и около половины низкоквалифицированных рабочих месте в ряде отраслей сельского хозяйства и строительства, и $46 \%$ исследователей в медицинской сфере. Совокупный доход только нелегальных иммигрантов оценивается в 350 млрд. \$, около трети из которых идёт на покупки, что стимулирует американскую розничную торговлю и приносит значительные налоговые поступления (Ford, 2007).

Экономический эффект от иммиграции для страны составляет лишь $0,1 \%$ совокупного национального продукта, в то время как иммиграция тормозит рост заработной платы, ведёт к снижению требований в сфере охраны труда и техники безопасности и создаёт серьёзную нагрузку на рынок труда, финансовые системы и социальные службы ведущих по количеству иммигрантов.

Нелегальные иммигранты не платят часть налогов, так же, как и их работодатели, что приводит к уменьшенному количеству налоговых сборов в США.

Затраты на постройку стены Трампа являются достаточно существенными даже для бюджета США. Примерная стоимость оценивается от 11 до 25 млрд. \$. Эта ситуация часто приводит к разногласию в Конгрессе. Также многие южные штаты вынуждены выделять какую-то часть своего бюджета. Дональд Трамп начал привлекать частные организации по строительству стены, которые вносят свои деньги в бюджет и строят стену на частных территориях.

Борьба с незаконной иммиграцией в США резко сократила число граждан центральноамериканских стран и других лиц, пытающихся въехать в Америку. Но мексиканцы, которые не были связаны с данными ограничениями (например, долгий путь из своей страны), стали появляться на границе в большем количестве. Мотивом во многих случаях называлась попытка спасения от проблемы насилия в Мексике. Тысячи людей постоянно застревают на несколько недель в СьюдадХуаресе и других пограничных городах, ожидая разрешения на въезд в Соединенные Штаты, чтобы подать прошение о предоставлении убежища. Данная процедура ожидания нарушает американское и международное право, заставляя мигрантов оставаться в стране, где они чувствуют, что ихжизнь находится под большой угрозой. Мигранты заявляют, что они опасаются находиться в своей же стране, потому что уровень преступности очень высок, особенно в приграничных городах, и местные бандитские группировки постоянно их атакуют или вымогают деньги. Многих 
принуждают вступить в группировки, а в случае отказа начинают преследования всей семьи. Поэтому часто мигранты подают прошение об убежище всей семьей. Иногда это может достигать 10, и 15 человек одновременно. Где бы они ни были бы в Мексике, банды могут найти их.

Администрация Трампа настойчиво стремилась сократить легальную и нелегальную иммиграцию путем введения ограничительных мер на въезд. Данные действия включают возвращение мигрантов из различных стран в Мексику, пока их иммиграционные дела рассматриваются в американских судах, и принуждают мигрантов сначала подать прошение о предоставлении убежища в странах, через которые они проезжали по пути в Соединенные Штаты.

Сегодня в Мексике наблюдается рекордный уровень убийств и преступности. В последние время все больше людей собираются у границы в попытках попросить убежища в Соединенных Штатах. Администрация Трампа также оказывает давление на мексиканское правительство, чтобы ужесточить борьбу с нелегальной миграцией, что привело к развертыванию тысяч сил безопасности Мексики, чтобы помочь в задержании мигрантов, когда они совершают свое передвижение на север страны. Данные меры привели к резкому сокращению числа мигрантов, пытающихся проникнуть в Соединенные Штаты. Однако эта политика мало повлияла на миграцию мексиканцев, поскольку им нельзя запретить передвигаться по их собственной стране к северной границе. Как только мексиканские беженцы, въехавшие в Соединенные Штаты, обратятся за предоставлением убежища, если их ходатайства не будут отклонены в США, по закону они уже не могут быть возвращены домой.

В то время как общее число мигрантов, арестованных вдоль юго-западной границы, сократилось, число задержанных мексиканцев возросло. Около 17 тысяч граждан Мексики были задержаны при пересечении границы между пропускными пунктами въезда в октябре 2019 г., что на 34\% больше, чем в июле 2019 г., по данным Таможенной службы и пограничной охраны Соединенных Штатов. Число мексиканцев, подающих прошение об убежище, также резко возросло в последние месяцы 2019 г. По мере того, как число беженцев повышалось, американские пограничники в основном отказывали просителям убежища на официальных таможенных пунктах, ссылаясь на то, что у них нет возможности принимать новых заявителей. Эта практика вынудила тысячи мексиканцев ожидать решения, находясь вдоль границы, пока им представится возможность доказать, то, что они имеют право на убежище в США.

Условия, в которых проживают мигранты возле границы, являются тяжелыми. В городе Сьюдад-Хуарес, они ночуют под пластиковыми брезентами в лагерях, которые находятся возле трех основных пограничных мостов. В этих местах очень экстремальный климат. Ночью сильно падает температура, и идут холодные ливневые дожди. Мексиканцы присоединились к многим тысячам просителей убежища из других стран, которые также были вынуждены ждать в Мексике после того, как Соединенные Штаты начали серьезно ограничивать число дел, которые они готовы принимать в день, из-за введения новой системы отбора лиц, просящих убежище.

Администрация Трампа сосредоточена на том, чтобы свести иммиграцию к нулю, но при этом она снова разрушает систему, созданную Конгрессом для защиты 
наиболее уязвимых мигрантов, прибывающих к границам США. Без уведомления она запустила программу в Эль-Пасо, предназначенную для ускорения судебных разбирательств мексиканских мигрантов, которые находятся в поисках убежища. Это также сделано для ускорения возврата отвергнутых заявителей на родину. Инициатива исходит от чиновников Национальной безопасности США, которые заявляют, что они были разочарованы ежедневными групповыми прорывами мексиканских мигрантов через границу.

Многие мигранты надеются, что правительство Соединенных Штатов смягчит свою политику по отношению к ним, чтобы больше людей могли находиться в безопасности. Списки находящихся в очереди, составленные самими мигрантами, определяют порядок пересечения границ семьями. В некоторые дни пропускают по несколько семей. Американские официальные лица связывают резкий рост числа мексиканцев, пытающихся пересечь границу, с изменением стратегии контрабандистов-мигрантов, которые видели, как их бизнес рушится по мере сокращения миграции из центральной Америки. Система, известная как «система учета», строго ограничивает число людей, которые могут обратиться за убежищем в течение одного дня. Считается, что семьям с маленькими детьми чаще предоставляют убежище, поэтому некоторые берут даже не своих детей для пересечения границы любой ценой.

Около двух десятков мигрантов, опрошенных в лагерях Сьюдад-Хуареса, заявили, что их решение не имеет ничего общего с маркетинговой привлекательностью контрабандистов. Все они сообщили, что они спасаются от насилия в своей стране. Известно, что сегодня во многих регионах Мексики произошло ухудшение уровня жизни из-за преступности, поэтому люди начали оттуда уезжать. Также многие мигранты преследуются в течение месяцев, если не лет, и совсем недавно узнали о возможности запросить убежище. Третья группа мигрантов мотивирована слухами о том, что американские власти разрешают въезд большему числу мексиканцев несмотря на то, что они ограничивают доступ в страну для жителей Центральной Америки и других стран. Также многие из мигрантов переходят границу нелегально, так как просто не могут больше ждать или получили отказ во въезде. Некоторые мигранты пользуются услугами мексиканских картелей, что приводит к очень печальным последствиям. Кроме того, что мигранты отдают свои последние деньги, чтобы попасть в США, иногда их заставляют перевозить запрещенные вещества, что является противозаконным, и при задержании они уголовно преследуются за нелегальное пересечение границы, а также за контрабанду запрещенных веществ.

Можно сказать, что система рассмотрения и обработки заявлений беженцев существуетнепросто так. КонгрессСШАтребует отадминистрации Трампаследовать определенному алгоритму, но они этого не делают, и тем самым подвергают тысячи людей потенциальному вреду, которому они никогда не должны были подвергаться.

В заключение стоит отметить, что проблема миграции в США, начиная с конца 1990-х годов, была серьезной задачей для правительства. Можно сказать, что сегодня страна, в какой-то степени, закрыта от легальной иммиграции, что также приводит к попыткам незаконного пересечения границы. Нынешняя администрация продолжает сокращать легальные возможности въехать в Соединённые Штаты Америки, а также ужесточила свою политику в отношении нелегальных мигрантов, попытки завершения программы DACA, и тех, кто подает прошение о 
предоставлении убежища. Экономическая ситуация в США сегодня вводит в трудную финансовую ситуацию вновь прибывших легальных, а тем более - и нелегальных мигрантов. Часто это приводит к повышению уровня преступности, но не только среди мигрантов, но и среди местного населения, которое эксплуатирует рабочих, не выплачивая им заработную плату, что является нарушений прав мигрантов. Права человека в данном вопросе играют не последнюю роль, так как беженцы, ожидающие решения властей США, находятся на опасной для них территории. Это нарушает международные законы, а также законодательство США, и является в какой-то степени странным, потому что Соединённые Штаты всегда выступают за права человека по всему миру и даже за права мигрантов. Об этом свидетельствуют: программа DACA, созданная Б. Обамой, право на воссоединение с семьей, имеющееся у нерезидентов, которые его используют для воссоединения со своими близкими.

Следствием таких противоречий на сегодняшний день стала жесткая политика Администрации Трампа для решения вопроса нелегальной иммиграции.

\section{СПИСОК ЛИТЕРАТУРЫ}

Ford, W. F. (2007) Immigrationomics: A Discussion of Some Key Issues // Economic Education Bulletin. Vol. 47, № 10, October. P. 2-5.

Дата поступления: 30.03.2020 г.

Улыбин Иван Сергеевич - магистрант факультета экономики, управления и международных отношений Московского гуманитарного университета. Адрес: 111395, Россия, г. Москва, ул. Юности, д. 5. Тел: +7 (926) 128-77-64. Эл. адрес: snake444@inbox.ru

Ulybin Ivan Sergeyevich, Graduate Student, Faculty of Economics, Management and International Relations, Moscow University for the Humanities. Postal address: 5, Yunosti St., Moscow, Russian Federation, 111395. Tel.: +7 (926) 128-77-64. E- mail: snake444@ inbox.ru

\section{Для цитирования:}

Улыбин И. С. Вызовы и угрозы современного мира на примере миграционного кризиса США // Научные труды Московского гуманитарного университета. 2020. №2. C. 43-49. DOI: 10.17805/trudy.2020.2.8 